\title{
Carbohydrates are the problem, end of story
}

\section{Opinion}

Pretty bold statement, yes! With the advent of social media, the sugar giants are not going to be able to escape the harm that sugar does in the human body. Some startling statistics, 20,000 die a day in US due to sugar related disease (diabetes, cancer, and heart disease), $50 \%$ of US population has Diabetes or on-set diabetes, $76 \%$ of population overweight and sadly $40 \%$ of our children are overweight and children diabetes growing at an exponential rate (\#1 form of child abuse in US is feeding our children sugar). I have studied Food Science my entire life, obtaining a minor in 1987 from SJSU, yet more important for me than studies is the fact I have had my body fat BELOW 5\%, 15 times in my life and helped 100's of others get their body fat below 5\%? It is very simple, lower your carbohydrates. Let me say it again, lower your carbohydrates. I ate cheese and bacon during each time that I got my body fat to that level. It is NOT about fat. Now the sugar giants that make money from selling you sugar, over 170 LBS per person per year, so they will argue this and DR's may argue this, yet I bet NONE of them have actually reduced their body fat and practice what they preach. I have had my blood work done $2 \mathrm{x}$ a year my entire life, and my blood work is all normal and in fact my cholesterol is 160 . Our bodies need and produce cholesterol, if your body fat is low, you will not have high cholesterol no matter how much you eat. I am currently 53 years old, $10 \%$ body fat and have the energy of a teenager! For the average person, I do not believe in a high protein diet, I believe increasing Protein by 100 grams and decreasing carbohydrates by 100 grams, with a high fiber diet. Study after study supports this, People with a high fat intake -- about 35 percent of their daily diet -- had a 23 percent lower risk of early death and 18 percent lower risk of stroke compared to people who ate less fat. A very low intake of saturated fats (below 3 percent of daily diet) was associated with a higher risk of death in the study, compared to diets containing up to 13 percent daily. High-carbohydrate diets have been linked with increases in both blood cholesterol and in the chemical building blocks of cholesterol, this I know from personal experience! With regard to FDA labelling, 016 NLEA Label - Added sugars are now listed when calories from fat have been removed. Evidence of sugar much more of a concern! I believe that FDA will put a warning like the surgeon general did with cigarettes, something like "more than 10 grams added sugar per serving has shown to cause diabetes, cancer and heart disease."

With information so readably available, the sugar companies can no longer hide from the on slot of class action lawsuits. $70 \%$ of caloric intake in lower social economic societies come from soda, which is killing people, not to mention the tooth decay (when a rotted tooth gets pulled, Novocain does not work, very sad for our youth). 10 times as many people die from sugar than from Alcohol and drugs combined. When I see a person allowing their children to drink soda, I want to say, why not give them Heroine, they will live longer. Added fructose (from corn syrup, high fructose corn syrup and a zillion other products) is a "chronic, dose-dependent liver toxin." In fact, they say that high fructose corn syrup damages the liver just like alcohol does. And on top of that, it's metabolized directly into fat, not energy! 100 years ago, no one was fat ${ }^{1-4}$ (Figure 1).

Vegan, Gutan Free, Non GMO, Organic all sound good, yet no one is dying from using or not using these forms of food. 20,000 will die today because of sugar, that need to be our focus. Yet food is a belief system like politic or religion and usually met with some form of upset

\author{
Volume 4 Issue 2 - 2017
}

\author{
William Hogarty \\ San Jose State University, USA
}

Correspondence: William Hogarty, San Jose State University, Livermore, California, USA, Tel 925518 1257,

Email whogarty@proofsmartfood.com

Received: October 27, 2017 | Published: November 30, 2017

or defence. My entire family has low body fat and low glucose levels (none diabetic), so if you want to be healthy and feel GREAT avoid sugar. It's pretty simple, avoid processed foods, get foods at close to the way they came out of the ground, pay attention to labels, look for more protein and less added sugar. Careful of Sugar Free (because artificial sweeteners) and AVOID soda! Avoid fruit juice (no fiber), avoid high amounts of milk (lots of sugar). Stevia is the only sugar alternative that is safe as it is plate based and natural. I have a passion to make a difference and developing a line of foods that have low net carbohydrates, low glycemic index, and simple understandable labels, it is truly a David and Goliath story and we would love your support! I will never support or produce a food unless I PERSONALLY use it daily. Currently I eat 2 Simply Delicious Protein Cookies and 2 Power Truffles a day!

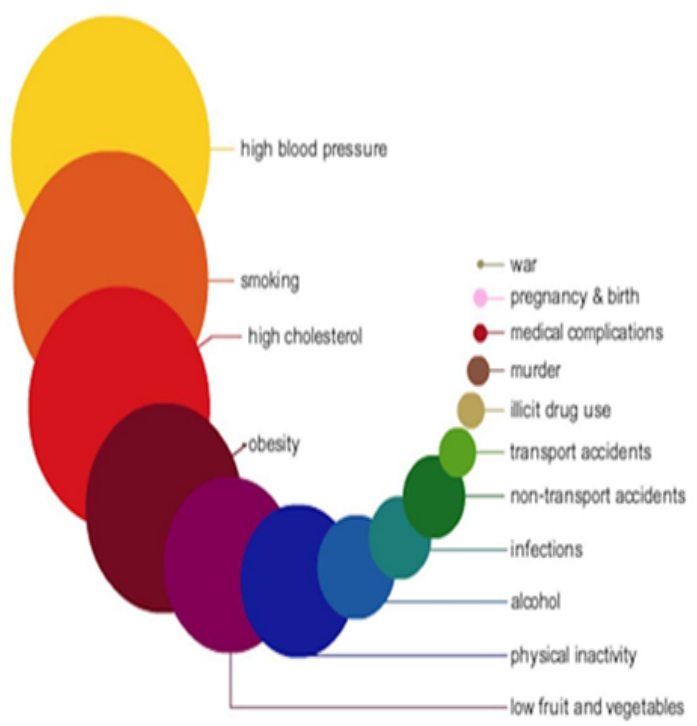

Figure I Risks leading to death in perspective.

\section{Acknowledgements}

None.

\section{Conflict of interest}

The author declares no conflict of interest. 


\section{References}

1. Mahshid Dehghan. An investigator with the Population Health Research Institute at McMaster University in Ontario. Canada;

2. Dennis Thompson. Large diet study suggests it's carbs, not fats, that are bad for your health. CBS News, USA; 2017.
3. Caitlin Dewey. We're losing more people to the sweets than to the streets: Why two black pastors are suing Coca-Cola. Wonkblog, USA; 2017.

4. Lin Carson, CEO and Founder. BAKER pedia and Eber Health. Portland. 